\title{
FRECUENCIAS DE CORTE Y NIVELES DE FERTILIZACIÓN NITROGENADA EN RENDIMIENTO Y CALIDAD DEL FORRAJE DE MORERA (Morus SP.), EN CUYUTA, GUATEMALA*
}

\author{
Carlos Rodríguez**, Juan A. Quiñonez ${ }^{* * *}$ y Rodrigo Arias****
}

\begin{abstract}
RESUMEN
En el Centro de Producción Agrícola de ICTA en Cuyuta, Escuintla, con el objeto de generar información sobre comportamiento productivo y calidad de forraje comestible de Morera (Morus sp.), se estudiaron tres frecuencias de corte: 6,9 y 12 semanas y tres niveles de fertilización nitrogenada 0,40 y $80 \mathrm{~kg} \mathrm{~N} / \mathrm{ha}$, se usó un diseño experimental de bloques completos al azar en un arreglo factorial $3 \times 3$, la altura de corte se hizo a $0,30 \mathrm{~m}$ sobre el nivel del suelo. Se realizaron dos secuencias de corte: 2 de agosto al 13 de septiembre y del 13 de septiembre al 6 de diciembre de 1990. En ambos casos la frecuencia de corte de 12 semanas y $80 \mathrm{~kg}$ de $\mathrm{N}$ fue superior a los demás $(\mathrm{P}<=0,01)$, con rendimientos de materia seca de 6,87 y 6,15 t/ha, los rendimientos de 9 semanas fueron estadísticamente superiores a los de 6 semanas, los porcentajes de proteína más altos se obtuvieron en los cortes de 6 semanas en planta entera, hojas y tallos. Los valores de digestibilidad in vitro de la materia seca, presentaron poca variabilidad entre tratamientos, los promedios para planta entera, hojas y tallo fueron: 65, 91 y $41 \%$ respectivamente. Lo anterior sugiere que la Morera (Morus sp) presenta un excelente potencial como suplemento balanceado (proteína y energía) para ganado bovino de doble propósito en la Costa Sur de Guatemala.
\end{abstract}

\begin{abstract}
The trial was conducted at the Centro de Producción Agrícola of ICfA in Cuyuta, Escuintla-Guatemala in order to generate information on the yield and quality of edible mulberry (Morus sp.) roughage treatments consisted of three harvest frequencies ( $6 ; 9$ and 12 weeks and three fertilization levels of nitrogen $(0.40$ and $80 \mathrm{~kg} / \mathrm{ha})$. A complete randomized block experimental design, with a factorial arrangement (3x3) was used. The cutting height was $0.3 \mathrm{~m}$ above the ground level with two sequencies: from August 2nd to September 13 th and from September 13th to December 6th, 1990. In both cases, the 12 week frequency cutting and $80 \mathrm{~kg}$ of $\mathrm{N}$ were superior to the others $(\mathrm{P}<=0.01)$, yielding 6.87 and $6.15 \mathrm{t} / \mathrm{ha}$ of dry matter respectively. The yields at 9 weeks were statistically higher than those at 6 weeks. The highest protein percentage of the whole plant, leaves and stalks were produced at 6 weeks. The dry matter digestibility values in vitro showed little variability among treatments, with averages for whole plants, leaves and stalks of 65,91 and $41 \%$, respectively. The preceeding data suggests that the mulberry has an excellent potential as a balanced supplement (protein and energy) for dual purpose cattle on the Southern coast of Guatemala.
\end{abstract}

\section{INTRODUCCIÓN}

El suministro de un nivel adecuado de proteína y energía para la producción de leche o carne es una limitante en el trópico seco, sobre todo durante la época seca.

Los concentrados comerciales pueden proporcionar una suplementación balanceada, pero su alto costo por unidad de nutrimentos así como en ocasiones su dudosa calidad y falta de disponibilidad en algunas localidades, hacen que estos no tengan posibilidad de utilizarse en sistemas de producción de ganado de doble propósito.

El Programa de Bovinos del ICTA, efectuó una búsqueda de alimentos de buena calidad y que puedan producirse en la misma finca. En 1989, se condujo un ensayo sobre la planta forrajera llamada (Morus sp), que de acuerdo a la literatura constituía una buena alternativa como suplemento alimenticio para bovinos de doble propósito en la Costa Sur de Guatemala.

La morera se ha utilizado principalmente para la alimentación del gusano de seda, pero en la actualidad su uso se está extendiendo como planta forrajera y para la construcción de cercas vivas. Los objetivos del presente trabajo son: determinar la frecuencia de corte y niveles de fertilización nitrogenada que optimicen la producción y calidad de la materia seca de morera y establecer el

\footnotetext{
* Trabajo presentado a la XXXVII Reunión Anual del PCCMCA. Panamá. 1991.

** Encargado del Programa Bovinos ICTA-Cuyuta, Guatemala.

*** 'Técnico Programa Bovinos ICTA-Cuyuta, Guatemala.

**** Director Técnico Unidad Producción Animal ICTA, Guatemala.
} 
potencial de la biomasa de morera, en términos de proteína cruda.

\section{MATERIALES Y MÉTODOS}

El presente trabajo se llevó a cabo del 21 de junio y finalizó el 6 de diciembre de 1990, en el Centro de Producción Agrícola de ICTA en Cuyuta, Masagua, Escuintla; la precipitación anual durante el experimento fue de $1075 \mathrm{~mm}$. La presente evaluación corresponde al segundo año de investigación.

El diseño experimental usado fue de bloques completos al azar con 3 repeticiones en un arreglo factorial $3 \times 3$. Tres frecuencias de corte: 6,9 y 12 semanas y tres niveles de fertilización nitrogenada 0,40 y $80 \mathrm{kgN} / \mathrm{ha}$. La altura de corte se efectuaron a $0,30 \mathrm{~m}$ sobre el nivel del suelo.

Se realizó un corte de nivelación el 21/junio/90 y se fertilizaron los tratamientos del 4 al 9 de julio. El corte de 6 semanas se realizó del 2/agosto/90, el de 9 semanas el 23/agosto y el 13/ septiembre e1 de 12 semanas. La segunda fase de evaluación se inició el 13/septiembre con el corte de 6 semanas, el 25/octubre el de 9 semanas y el 6/diciembre del mismo año el de 12 semanas.

Como fuente de nitrógeno se utilizó Urea al 46\%, que se adicionó alrededor de la mata en una pequeña zanja, que luego fue cubierta con suelo. El forraje verde se pesó en el campo. La determinación de materia seca se efectuó a 602 durante 48 horas y se fraccionaron las porciones para determinar relación hoja-tallo.

La determinación de proteína cruda y 'gestibilidad in vitro de la materia seca (DIVMS), se fectuó en el INCAP.

Las variables de respuesta fueron: forraje verde, materia seca, proteína cruda, DIVMS y relación hoja/tallo.

\section{RESULTADOS Y DISCUSIÓN}

En la Figura 1, se muestra el comportamiento de precipitación pluvial durante el ensayo. Puede observarse que el corte de 9 semanas de la segunda se de evaluación fue el que recibió la mayor ntidad de lluvia.

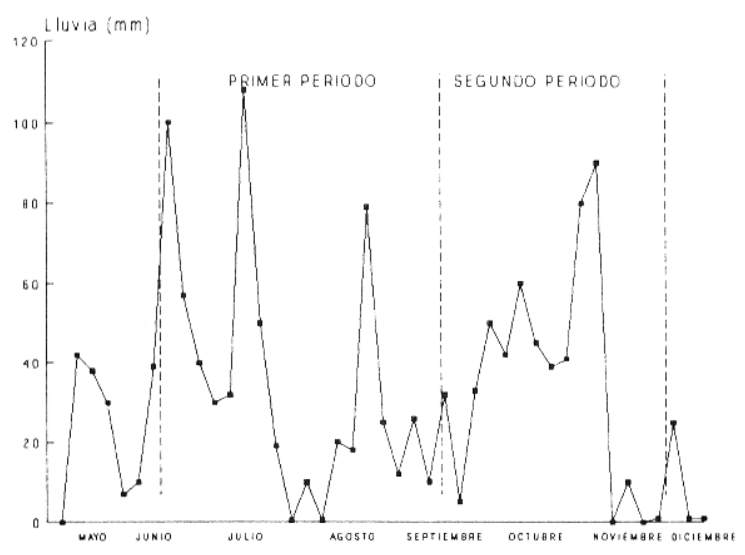

Figura 1. Precipitación pluvial de mayo a diciembre en Cuyuta, Masagua y Escuintla. 1990.

En el Cuadro 1, se presentan los rendimientos de forraje verde y materia seca obtenida en la primera y segunda secuencia de corte. Se puede apreciar que hay una tendencia clara de aumento en la producción de forraje a medida que se incrementa el nivel de nitrógeno y la frecuencia de corte.

Cuadro 1. Producciones promedio $\mathrm{t} / \mathrm{ha}$ de dos cortes de forraje verde y materia seca de Morera (Morus sp.) Cuyuta, 1990.

\begin{tabular}{|c|c|c|c|c|c|}
\hline \multirow{3}{*}{\multicolumn{2}{|c|}{$\begin{array}{l}\text { Tratamiento } \\
\text { N*. F.* }\end{array}$}} & \multicolumn{2}{|c|}{ PRIMER CORTE } & \multicolumn{2}{|c|}{ SEGUNDO CORTE } \\
\hline & & Forraje & Materia & Forraje & Materia \\
\hline & & Verde & Seca & Verde & Seca \\
\hline 0 & 6 & 1,96 & 0,47 & 1,58 & 0,47 \\
\hline 0 & 9 & 3,79 & 1,19 & 3,08 & 0,90 \\
\hline 0 & 12 & 5,11 & 2,00 & 5,20 & 1,97 \\
\hline 40 & 6 & 6,08 & 1,34 & 4,41 & 1,13 \\
\hline 40 & 9 & 7,67 & 2,46 & 7,45 & 2,25 \\
\hline 40 & 12 & 14,48 & 5,57 & 14,32 & 5,07 \\
\hline 80 & 6 & 6,63 & 1,45 & 4,83 & 1,19 \\
\hline 80 & 9 & 12,10 & 3,63 & 11,56 & 3,07 \\
\hline 80 & 12 & 18,52 & 6,87 & 18,66 & 6,15 \\
\hline
\end{tabular}

$\mathrm{N}=$ Niveles de Nitrogeno

$F=$ Frecuencia de Corte en Semanas.

En la producción de materia seca del primero y segundo corte la frecuencia de 12 semanas fue superior a la de 9 y ésta a la de 6; además el nivel de $80 \mathrm{~kg}$ de $\mathrm{N}$ fue superior al de 40 y éste al de $0 \mathrm{~kg} \mathrm{~N} / \mathrm{ha}, \mathrm{P}<=0,0 \mathrm{l}$ (Figura 2).

El análisis combinado de las dos épocas obtuvo una respuesta similar a la encontrada en los análisis individuales, indicándonos también que el rendimiento de la primera época fue superior a la segunda, pero hubo una distribución diferente de lluvia por frecuencia de corte que pudo influir en este resultado (Figura 1). 


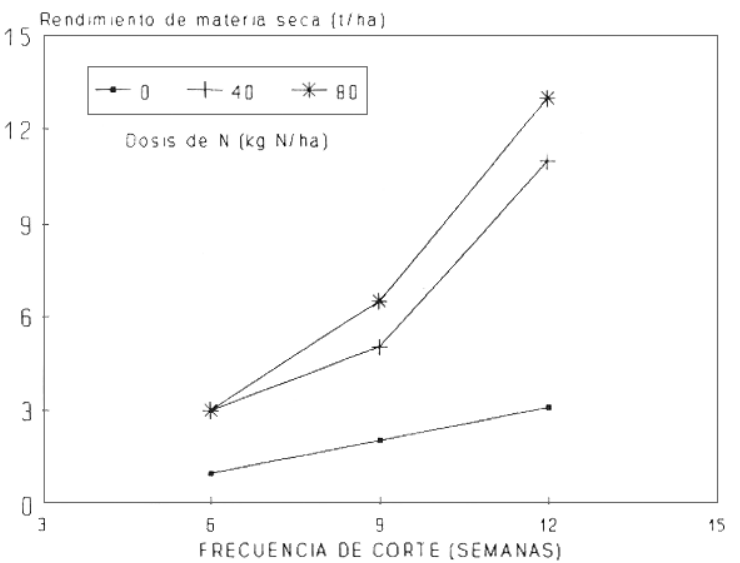

Figura 2.Efecto de las dosis de nitrógeno y la frecuencia de corte en la producción de materia seca de Morera. 1990.

Los contenidos de proteína cruda para planta entera, hojas y tallos de la primera secuencia de cortes, se puede apreciar en el Cuadro 2. La proteína cruda tendió a disminuir a medida que la frecuencia de corte fue más frecuente. La fertilización nitrogenada parece haber tenido poco efecto sobre el porcentaje de proteína cruda.

Cuadro 2. Contenido de proteína cruda (\%) por componente de Morera en el primer ciclo de corte, Cuyuta, 1990.

\begin{tabular}{lllll}
\hline & & \multicolumn{3}{c}{ PORCENTAJE DE PROTEINA } \\
\multirow{2}{*}{$\begin{array}{l}\text { Tratamiento } \\
N^{* *}\end{array}$ F $^{* *}$} & \multicolumn{3}{c}{ CRUDA POR COMPONENTE } \\
\cline { 2 - 5 } 0 & 6 & 14,19 & 20,92 & 6,33 \\
0 & 9 & 8,63 & 14,32 & 3,46 \\
0 & 12 & 9,19 & 12,70 & 3,26 \\
40 & 6 & 15,12 & 25,00 & 6,60 \\
40 & 9 & 8,68 & 13,39 & 3,18 \\
40 & 12 & 5,67 & 13,15 & 3,28 \\
80 & 6 & 16,63 & 24,01 & 6,58 \\
80 & 9 & 12,74 & 16,89 & 3,68 \\
80 & 12 & 7,88 & 10,37 & 3,15 \\
\hline \multirow{2}{*}{ Prom. } & $10,97 \pm 3,53$ & $16,75 \pm 5,00$ & $4,39 \pm 1,50$ \\
\hline
\end{tabular}

$*=\mathrm{Nivel}$ de $\mathrm{N} \mathrm{kg/ha}$

$* *$ = Frecuencia de Corte (Semanas)

Los porcentajes de proteína cruda variaron de 5,67 a 16,63 para planta entera, en hojas de 10,37 a $25,00 \%$ (Cuadro 2) y la DIVMS varió de 49,01 a 72,44\% para planta entera y de 90,06 a 94,00\% para hojas (Cuadro 3). Hay que establecer un buen manejo para explotar el verdadero potencial de esta planta como suplemento balanceado (proteína y energía) para la alimentación de ganado bovino de doble propósito.
Cuadro 3. Contenido de materia cruda (DIVMS) por componente de morera en el ciclo de cortes, Cuyuta, 1990.

\begin{tabular}{|c|c|c|c|c|}
\hline \multicolumn{2}{|c|}{ Tratamiento } & \multicolumn{3}{|c|}{$\begin{array}{r}\text { PORCENTAJE DE PROTEINA } \\
\text { CRUDA POR COMPONENTE } \\
\end{array}$} \\
\hline $\mathrm{N}^{\mathrm{k}}$ & $F * *$ & Planta entera & Hojas & Tallos \\
\hline 0 & 6 & 72,44 & 90,75 & 45,96 \\
\hline 0 & 9 & 66,36 & 94,00 & 45,95 \\
\hline 0 & 12 & 65,91 & 90,06 & 40,25 \\
\hline 40 & 6 & 67,57 & 89,42 & 41,46 \\
\hline 40 & 9 & 64,52 & 93,62 & 40,26 \\
\hline 40 & 12 & 49,01 & 90,58 & 34,04 \\
\hline 80 & 6 & 70,23 & 91,26 & 45,49 \\
\hline 80 & 9 & 71,64 & 93,01 & 38,27 \\
\hline 80 & 12 & 58,95 & 90,16 & 36,34 \\
\hline \multicolumn{2}{|c|}{ Prom. } & $65,18 \pm 6,90$ & $91,43 \pm 1,59$ & $40,89 \pm 4,06$ \\
\hline
\end{tabular}

* = Nivel de $\mathrm{N} \mathrm{kg/ha.}$

$* *=$ Frecuencia de Corte (Semanas).

La relación hoja-tallo en ambas faces de evaluación durante 1990 fueron de $(30,83: 1$ y 0,88:1) para planta entera y hojas, respectivamente (Cuadro 4), fue inferior a la registrada en el primer corte del año anterior (1,90:1), esto se explica porque en esa oportunidad las plantas estaban recién sembradas y ahora es una plantación bien establecida.

Cuadro 4. Relación hoja tallo de los dos cortes efectuados durante 1990, Cuyuta.

\begin{tabular}{llll}
\hline \multirow{2}{*}{$\begin{array}{l}\text { TRATAMIENTO } \\
\mathrm{N}^{* *}\end{array}$} & \multicolumn{2}{c}{ RELACION HOJA/TALLO } \\
\cline { 3 - 4 } & & Planta entera & Hojas \\
\hline 0 & 6 & $1,47: 1$ & $1,75: 1$ \\
0 & 9 & $1,01: 1$ & $1,03: 1$ \\
0 & 12 & $0,60: 1$ & $0,62: 1$ \\
40 & 6 & $1,02: 1$ & $1,23: 1$ \\
40 & 9 & $0,80: 1$ & $0,68: 1$ \\
40 & 12 & $0,47: 1$ & $0,46: 1$ \\
80 & 6 & $0,97: 1$ & $1,17: 1$ \\
80 & 9 & $0,64: 1$ & $0,60: 1$ \\
80 & 12 & $0,47: 1$ & $0,42: 1$ \\
\hline Promedio & & $0,83: 1$ & $0,88: 1$ \\
Desviacion & Estandar & 0,31 & 0,42 \\
\hline
\end{tabular}

El rendimiento de materia seca obtenido con aplicación de $80 \mathrm{~kg} \mathrm{~N} / \mathrm{ha}$ y frecuencia de corte de 12 semanas en ambas épocas $(6,87$ y $6,15 \mathrm{~kg} / \mathrm{ha})$ triplicaron el rendimiento del año anterior en el que se produjeron 2 t/ha, esto se debió a que las plantas se habían consolidado, habiendo desarrollado más el sistema radicular y engrosado más los tallos, también supera al obtenido en Italia, por Bonciarelli y Santilocchi (1990), quienes obtuvieron 4,05 t/ha, este último es superior al obtenido en el presente trabajo con aplicación de $80 \mathrm{~kg}$ de N/ha y frecuencia de 9 semanas (3,63 y 3,07 t/ha). 
En China (Xi-Jin y Popp, 1990) fertilizando con 1209 $\mathrm{kg}$ de N/ha en forma de Urea obtuvieron 32,7 t/ha de follaje comparado con $36 \mathrm{t}$ de forraje verde producido en el presente trabajo (incluyendo la planta entera) cuando se aplicaron $80 \mathrm{~kg}$ de $\mathrm{N}$ en 2 cortes de 12 semanas.

\section{CONCLUSIONES}

Con la frecuencia de 12 semanas y nivel de $80 \mathrm{~kg}$ $\mathrm{N} / \mathrm{ha}$ se obtuvieron los mayores rendimientos de biomasa de morera, este rendimiento casi duplicó al de 9 semanas. A medida que se incrementó el tiempo, la calidad de la planta bajó en términos de proteína cruda, esto implica el establecimiento de un punto donde se reduzca el rendimiento, pero se obtenga material de buena calidad.

\section{RECOMENDACIONES}

La morera es una planta con excelente potencial para la alimentación de bovinos, se recomienda estudiar la posibiliadad de que sea pastoreada directamente en el campo, realizar trabajos para evaluar su potencial en producción animal (carne o leche); estudiar su combinación con leguminosa de crecimiento corto que le aporten nitrógeno.

\section{LITERATURA CITADA}

BONCIARELLI, F; SANTILOCCHI, R 1990. First results of trials with forage shrubs for pasture. Rivista di Agronomia. 14, 21 25. Instituto di Agronomi generali e Coltivaziani erbacee. Universita di Perugia, Italia.

LUO XI - JIN.; THOMAS POPP. 1990. Nitrofoska en plantas de morera. Ensayos de campo en la República Popular de China. BASF Reportes Agrícolas 3 p. 